\title{
The selective enhancer substance (-)-BPAP counteracts the histological and functional consequences of an experimental stroke in rats
}

\author{
László Dénes* and Ildikó Miklya
}

Address: Department of Pharmacology and Pharmacotherapy, Semmelweis University, Budapest, Hungary

Email: László Dénes* - dr.denes@qmail.com

* Corresponding author

\author{
from I3th Scientific Symposium of the Austrian Pharmacological Society (APHAR). Joint Meeting with the Austrian Society of Toxicology (ASTOX) and the \\ Hungarian Society for Experimental and Clinical Pharmacology (MFT) \\ Vienna, Austria. 22-24 November 2007 \\ Published: 14 November 2007 \\ BMC Pharmacology 2007, 7(Suppl 2):A32 doi:10.| | 86/|47|-22 I0-7-S2-A32
}

This abstract is available from: http://www.biomedcentral.com/I47I-2210/7/S2/A32

(c) 2007 Dénes and Miklya; licensee BioMed Central Ltd.

The effect of the newly developed, up to the present most potent and selective enhancer substance, $R-(-)-1$-(benzofuran-2-yl)-2-propylaminopentane [(-)-BPAP], was studied in rats exposed to an experimental stroke. Permanent focal ischemia was induced by cortical photothrombosis in Wistar rats with Rose Bengal $(20 \mathrm{mg} / \mathrm{kg}$, i.v. $)$, irradiated by a cold light source for $10 \mathrm{~min}$. Rats were treated daily with (-)-BPAP $(0.2 \mathrm{mg} / \mathrm{kg}$, i.p.) for 3 days. The infarction was visualized with $2 \%$ TTC. The lesion size was evaluated by morphometry using image analysis software (AxioVison/Zeiss). The effect of (-)-BPAP on the learning ability of rats was measured in the shuttle box. The acquisition of a two-way conditioned avoidance reflex (CAR) was analyzed during 5 consecutive days. The rats were trained with 100 trials per day. The light-irradiation for $10 \mathrm{~min}$ after injection of Rose Bengal caused well-demarcated tissue damage in the cerebral cortex and decreased the performance of the lesioned rats in the shuttle box. (-)-BPAP treatment caused a statistically significant reduction of the infarct size (from $1.190 \pm 0.096 \mathrm{~mm}^{2}$ to $0.256 \pm 0.057$ $\mathrm{mm}^{2} ; \mathrm{n}=18$ ) and improved the performance of the rats $(45.75 \pm 15$ to $75.67 \pm 7.2 ; \mathrm{n}=12)$. The data are in excellent harmony with the series of papers which described the protective effect of (-)-BPAP in various types of enhancer-sensitive cultured cells.

\section{Acknowledgements}

This work was supported by the Health Scientific Council (ETT I40/2003, ETT 606/2006). 